\title{
Synthesis, Characterization, and Stability Evaluation of $\beta$-Carotene Encapsulated in Starch-Chitosan/Tripolyphosphate Matrices
}

\author{
Agnes Dyah Novitasari Lestari ${ }^{1,2, *}$, Dwi Siswanta ${ }^{2}$, Ronny Martien ${ }^{3}$, and Mudasir Mudasir ${ }^{2, * *}$ \\ ${ }^{1}$ Department of Chemistry, Faculty of Mathematics and Natural Sciences, Universitas Papua, \\ Jl. Gunung Salju, Amban, Manokwari 98314, Indonesia \\ ${ }^{2}$ Department of Chemistry, Faculty of Mathematics and Natural Sciences, Universitas Gadjah Mada, \\ Sekip Utara, Yogyakarta 55281, Indonesia \\ ${ }^{3}$ Department of Pharmaceutics, Faculty of Pharmacy, Universitas Gadjah Mada, \\ Sekip Utara, Yogyakarta 55281 Indonesia
}

* Corresponding author:

email:a.dyahnovitasari@gmail.com; mudasir@ugm.ac.id

Received: October 8, 2019

Accepted: February 20, 2020

DOI: $10.22146 /$ ijc.50449

\begin{abstract}
This study aims to investigate the synthesis and characterization of $\beta$-carotene encapsulated in the blending matrices of starch (native and hydrolyzed starch)chitosan/TPP (tripolyphosphate) by examining the effects of starch-to-chitosan weight ratio, $\beta$-carotene addition level, and TPP addition level on the encapsulation efficiency (EE) and loading capacity (LC); and to evaluate their storage stability. The encapsulation was done by the dropwise addition of ethanolic $\beta$-carotene dispersion into the blending matrices. The results of XRD analysis show that the encapsulation process significantly decreases the crystallinity of the starches, chitosan, and $\beta$-carotene. Scanning electron microscope (SEM) images reveal that the encapsulation products form irregular lumps. The EE and LC tend to increase with the increase in polymer fraction of matrices and $\beta$-carotene addition level, and with the decrease in TPP addition level. The addition of chitosan and the replacement of native starch by hydrolyzed starch tend to increase storage stability of $\beta$-carotene encapsulated in the starch matrix because chitosan can act as a good film-forming and antioxidant, while hydrolyzed starch contains amylose amylopectin with a short chain which is better in film-forming ability. These results promote the use of the hydrolyzed starch-chitosan/TPP as a matrix to enhance the stability $\beta$-carotene via encapsulations.
\end{abstract}

Keywords: starch; chitosan; TPP; $\beta$-carotene; encapsulation

\section{- INTRODUCTION}

Encapsulation of active compounds is an important research topic that has attracted many researchers until recently. Encapsulation is a way to wrap the active substance in order to increase its stability, solubility, bioavailability, and the delivery of the active substance in the body and any desired medium [1-2]. In an encapsulation study, the wrapped material is called the core, while the wrapper is called a matrix. Various matrix materials have been used in the encapsulation process, such as surfactants, synthetic polymers, and natural polymers, including proteins, lipids, and carbohydrates [3].
$\beta$-Carotene is one of the main carotenoid compounds and is an active compound that contributes significantly to human health, i.e., as a pro-vitamin A, an antioxidant, and an anticancer agent. Unfortunately, $\beta$-carotene is unstable to light, heat, and oxygen [4]. To improve the stability of $\beta$-carotene, numerous researchers have tried to encapsulate $\beta$-carotene in various matrices to produce liquid or solid products that are easier to be handled. For example, $\beta$-Carotene has been encapsulated in the form of oil-in-water $(\mathrm{O} / \mathrm{W})$ nano-emulsions with polysorbate tween as an emulsifier using high-pressure homogenization. At $25^{\circ} \mathrm{C}$, the stability of $\beta$-carotene decreased after four weeks, with a relatively slight loss of

Agnes Dyah Novitasari Lestari et al. 
$\beta$-carotene content [5]. In another study, a biosurfactant of egg white protein was applied to improve the physicochemical stability of $\beta$-carotene emulsions. The stability of $\beta$-carotene found to increase up to approximately $80 \%$ on day 30 by using this biosurfactant [6]. Encapsulation using surfactants produced high encapsulation efficiency, but the stability of the encapsulation products is relatively low with regard to temperature and dilution. In addition, certain surfactants have been reported to be toxic at high concentrations [7]. Polymers could be used to replace surfactant, but synthetic polymers show low biocompatibility within the body and had a risk of becoming toxic. Natural polymers have advantages as a matrix of encapsulation since they are biocompatible, biodegradable, and non-toxic, even in high concentrations [8-9]. In the previous study, $\beta$-carotene has been encapsulated in natural polymers such as starch, maltodextrin, and modified starch [10]. The use of modified (acid hydrolyzed) starch has been proved to be able to increase the storage stability of $\beta$ carotene. A similar result has also been reported in the use of hydrolyzed pinhão (Araucaria angustifolia seeds) starch to increase the storage stability of microencapsulated $\beta$-carotene [11].

Meanwhile, the ability of starch as an encapsulating matrix can also be increased by mixing starch with other compatible polymers. For example, starch could be combined with chitosan to produce a compatible matrix [12-13]. Chitosan and its derivatives have various advantages as matrix materials, as chitosan has antibacterial and antioxidant activities, increases mechanical strength, and tends to be degraded in the small intestine [14-15]. A combination of starch and chitosan polymers could increase composite mechanical strength and resist to high temperatures as well as reduce the rate of amylose release [16]. The polymer combination also produced material that was more resistant to ultraviolet (UV) light in comparison with those using the native starch [17].

The study investigated the effects of the weight ratio of native starch to chitosan on the yield, color, Fourier Infra-Red (FTIR) spectra, optical microscope image, and particle size of the encapsulation products. The preliminary study showed that $\beta$-carotene has been successfully encapsulated in native starch-chitosan/TPP blending matrices producing micro size encapsulation products. Continuing our preliminary research [18], The objectives of this research are (1) to characterize the products of $\beta$-carotene encapsulation in the matrices of native starch-chitosan/TPP and acid hydrolyzed starchchitosan/TPP using Scanning Electron Microscopy (SEM) and X-ray diffractometry (XRD), (2) to study the effect of starch/chitosan weight ratio, $\beta$-carotene and TPP addition level on the encapsulation efficiency (EE) and loading capacity (LC), and (3) to investigate the effects of light and heat on the $\beta$-carotene stability stored as encapsulation products. As far as we know, our report is original and unique because it is different from the previous reports [10-11]. Here, we have used corn starch, modified the matrice by chitosan addition, studied the effect of the use of hydrolyzed starch instead of native starch, used the solvent displacement method in the synthesis process, and applied freeze-dry in the drying step.

\section{- EXPERIMENTAL SECTION}

\section{Materials}

Corn starch, chitosan, TPP, and $\beta$-carotene were purchased from Sigma Aldrich. Glacial acetic acid and absolute ethanol were purchased from Merck. All materials were used as received without further purification.

\section{Instrumentation}

A Sorvall biofuge primo $\mathrm{R}$ refrigerated centrifuge and a Leybold-Heraeus freeze dryer Lyovac GT 2 were used in the preparation of microparticle. The morphology of obtained microparticle was analyzed by using a scanning Electron Microscopy (SEM, JEOL Model JSM-6510LA) and a Transmission electron microscopy (TEM, JEM-1400 JEOL 120 kV). XRD pattern was measured by using a Pananalytical diffractometer with Bragg Brentano geometry and $\mathrm{CuKa}$ radiation $(\lambda=0.1542 \mathrm{~nm}, 40 \mathrm{kV}, 30 \mathrm{~mA})$. The determination of $\beta$-carotene content was performed by measuring the absorbance of $\beta$-carotene in hexane using 
a Shimadzu UV 1800 spectrophotometer at $450 \mathrm{~nm}$. A storage chamber with a size of $48 \times 37 \times 44 \mathrm{~cm}^{3}$ which was equipped with two Gaxindo BLB-T5/6W UV Lamps $(\lambda=$ $365 \mathrm{~nm}$ ) separated at a distance of $2 \mathrm{~cm}$ was used to test the effects of UV light on the storage stability of $\beta$-carotene encapsulation.

\section{Procedure}

\section{Synthesis of hydrolyzed starch}

The synthesis of hydrolyzed starch was carried out in accordance with the previous reports [18-19] as follows. As much as $100 \mathrm{~g}$ of starch was added to $500 \mathrm{~mL}$ of $0.15 \mathrm{M} \mathrm{HCl}$, and the mixture was stirred by using a magnetic stirrer for $8 \mathrm{~h}$ while maintaining a temperature of $50{ }^{\circ} \mathrm{C}$. The hydrolyzed starch was filtered, and the obtained residue was then washed 4 times with distilled water and dried for $48 \mathrm{~h}$ at $50{ }^{\circ} \mathrm{C}$ [18].

\section{Encapsulation process}

The encapsulation process was performed in a similar procedure to our previous work [19] except that the compositions and concentrations of TPP and $\beta$-carotene were varied. The matrix mixture of starchchitosan/TPP was prepared as described in the literature [20] with slight modifications. A certain amount of volume (according to the weight ratio of starch and chitosan) of cationic solution ( $1 \% \mathrm{w} / \mathrm{v}$ chitosan) was added to the TPP-starch mixture (prepared by adding water in starch followed by the boiling process) with the compositions as described in Table 1. The encapsulation process was carried out based on the method of the literature [21] with minor modifications. The matrix mixture $(220 \mathrm{~mL})$ was heated and stirred in a water bath at $90{ }^{\circ} \mathrm{C}$ for $10 \mathrm{~min}$, followed by the addition of $100 \mathrm{~mL}$ of a certain amount of ethanolic $\beta$-carotene dispersion as given in Table 1 dropwise while continually stirred. The mixtures were then cooled at room temperature and were added with another $100 \mathrm{~mL}$ of ethanolic $\beta$-carotene dispersion of the same concentration as that used in the previous step. Then, the mixture was centrifuged, dried in freeze-dryer, crushed, and sieved 200 mesh.

\section{Determination of $\beta$-carotene content}

$\beta$-Carotene content in capsules was determined by the method described in the literature [5,22] with slight modifications. A total of $5 \mathrm{mg}$ of sample was dispersed in $1 \mathrm{~mL}$ of $2 \mathrm{M} \mathrm{HCl}$, heated in a water bath at $75^{\circ} \mathrm{C}$ for $3 \mathrm{~min}$, cooled and added with $2 \mathrm{~mL}$ of ethanol and $3 \mathrm{~mL}$ of hexane in a test tube. The mixture in the tube was then shaken using vortex until the powder had been bleached. This step was repeated several times and then stopped when all the $\beta$-carotene had been extracted. Furthermore, the supernatant was taken, and absorbance of the hexane fraction was measured at $450 \mathrm{~nm}$ with a UV-Vis spectrophotometer. The concentration of the $\beta$-carotene

Table 1. Sample formulation

\begin{tabular}{cccccc}
\hline $\begin{array}{c}\text { Formulation } \\
\text { code }\end{array}$ & $\begin{array}{c}\text { Weight ratio of } \\
\text { starch to chitosan }\end{array}$ & $\begin{array}{c}\text { Volume of } 1 \% \text { starch } \\
\text { dispersion }(\mathrm{mL})\end{array}$ & $\begin{array}{c}\text { Volume of } 1 \% \text { chitosan } \\
\text { solution }(\mathrm{mL})\end{array}$ & $\begin{array}{c}\beta \text {-carotene added in } \\
200 \text { mL ethanol }(\mathrm{mg})\end{array}$ & $\begin{array}{c}\text { TPP added in } 20 \mathrm{~mL} \\
\text { solution }(\mathrm{mg})\end{array}$ \\
\hline Fx0 & 1.00 & 100 & 100 & 0 & 600 \\
Fx1 & 0.25 & 60 & 140 & 10 & 600 \\
Fx2 & 0.43 & 40 & 160 & 10 & 600 \\
Fx3 & 1.00 & 100 & 100 & 10 & 600 \\
Fx4 & 2.33 & 160 & 40 & 10 & 600 \\
Fx5 & 4.00 & 140 & 60 & 10 & 600 \\
Fx6 & 1.00 & 100 & 100 & 5 & 600 \\
Fx7 & 1.00 & 100 & 100 & 15 & 600 \\
Fx8 & 1.00 & 100 & 100 & 20 & 600 \\
Fx9 & 1.00 & 100 & 100 & 10 & 400 \\
Fx10 & 1.00 & 100 & 100 & 10 & 500 \\
Fx11 & 1.00 & 100 & 100 & 10 & 700 \\
Fx12 & 1.00 & 100 & 100 & 10 & 800 \\
\hline
\end{tabular}

$\mathrm{x}=\mathrm{N}$ or $\mathrm{H}, \mathrm{FN}=$ native starch based formulation, $\mathrm{FH}=$ hydrolyzed starch based formulation 
was determined based on the standard curve of $\beta$-carotene that was obtained in the same way as the sample. Loading capacity (LC) and encapsulation efficiency (EE) were calculated by using Eq. (1) and (2).

$\mathrm{LC}(\mathrm{mg} / \mathrm{g})=\frac{\mathrm{mBC}}{\mathrm{mMP}}$

$\mathrm{EE}(\%)=\frac{\mathrm{mBC}}{\mathrm{mTBC}} \times 100$

where, $\mathrm{mBC}=$ mass of $\beta$-carotene encapsulated in the microparticle $(\mathrm{mg}), \mathrm{mMP}=$ mass of microparticle $(\mathrm{g})$, $\mathrm{mTBC}=$ total mass of $\beta$-carotene in theoretical loading (mg).

\section{Storage stability test}

The storage stability of the encapsulation products was tested according to the literature [11] with slight modifications. The encapsulation products were stored in a dark storage vessel placed in a refrigerator $(5 \pm 1)^{\circ} \mathrm{C}$ and in an ambient temperature chamber $(30 \pm 1)^{\circ} \mathrm{C}$. In order to investigate its stability against $\mathrm{UV}$ irradiation, the encapsulated $\beta$-carotene samples were placed in a UV chamber which furnished with a pair of UV light tube BLB-T5/6W, $\lambda=365 \mathrm{~nm}$ at ambient temperature. The samples were placed at a distance of $7 \mathrm{~cm}$ below the lamps. The concentration of $\beta$-carotene was determined once every week for 6 weeks using a UV-Vis spectrophotometer. The storage stability was expressed as the residual rate in a percent: $\mathrm{w}_{\mathrm{t}} / \mathrm{w}_{0}$, where $\mathrm{w}_{\mathrm{t}}$ was the weight of $\beta$-carotene after storage during the time interval $t$, and $\mathrm{w}_{0}$ was the initial weight of $\beta$-carotene.

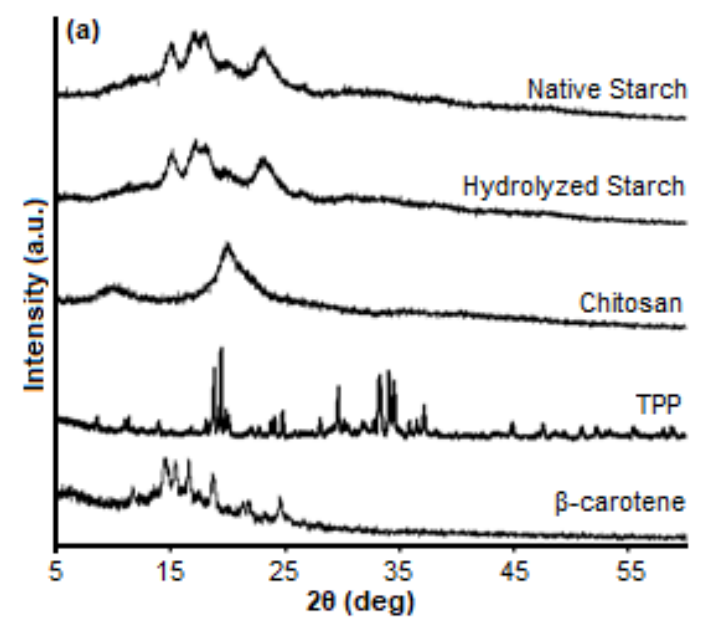

\section{- RESULTS AND DISCUSSION}

\section{XRD Analysis}

The diffraction patterns of starches, chitosan, TPP, and $\beta$-carotene (Fig. 1(a)) show semicrystalline structures, and their characteristic peaks of $2 \theta$ are listed in Table 2. The diffraction pattern of hydrolyzed starch shows a slight decrease in crystallinity compared with that of the native starch. This fact may indicate the increase of a shorter chain of amylose in hydrolyzed starch $[10,25]$. In addition, amylopectin depolymerization resulting from starch hydrolysis increased the quantity of linear chains similar to amylose [26-27]. In X-ray diffractograms of starch, the crystalline regions of the starch are dominated by aggregated double helices of amylopectin chains, while the amorphous regions are greatly composed of amylose. The increase in the quantity of linear chains similar to amylose may increase the amorphous region of hydrolyzed starch. Hence, the shorter chains of amylose and linear chains similar to amylose can participate in double helices with amylopectin, reducing the crystallinity of the starch granules [28].

Moreover, the X-ray diffraction pattern of the blending of starch-chitosan/TPP matrices depicted in Fig. 1(b) clearly shows a significant decline in its crystallinity indicated by the presence of a widening peak at $2 \theta$ of 19.89 for native starch-chitosan/TPP and 6.88, $11.82,18.56$, and 34.44 for hydrolyzed starchchitosan/TPP. The fact that the peaks in the blending

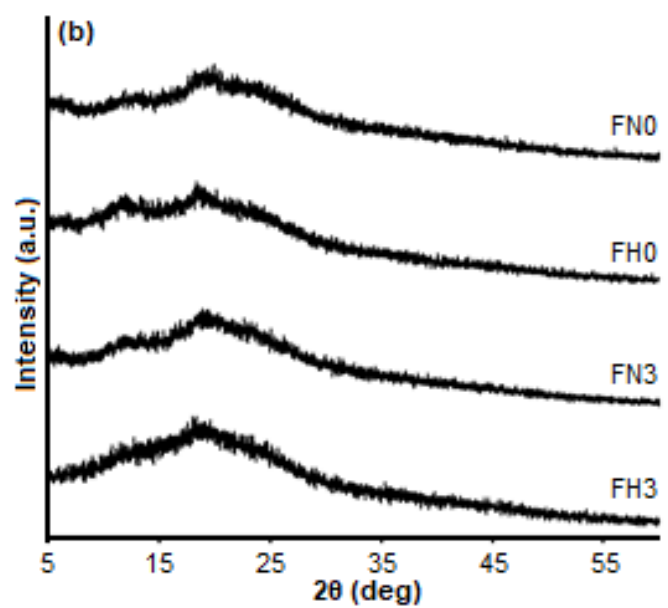

Fig 1. XRD pattern of materials (a) starch, hydrolyzed starch, chitosan, TPP, and $\beta$-carotene; (b) blended matrices without $\beta$-carotene (FN0 and FH0), and encapsulation products (FN3 and FH3) 
Table 2. The $2 \theta$ peaks of materials analyzed by XRD

\begin{tabular}{lrrrrrrrr}
\hline Materials & \multicolumn{10}{c}{$2 \theta$} \\
\hline Native Starch & 9.95 & 14.88 & 17.16 & 18.02 & 20.09 & 23.22 & 26.68 & 38.37 \\
Hydrolyzed starch & 15.12 & 17.17 & 18.18 & 20.07 & 26.61 & 30.28 & & \\
Chitosan & 20.55 & & & & & & & \\
TPP & 18.78 & 19.37 & 19.78 & 20.05 & 24.71 & 24.78 & 29.60 & 33.17 \\
& 33.28 & 34.05 & 34.49 & 37.08 & & & & \\
$\beta$-carotene & 11.07 & 14.49 & 15.41 & 16.61 & 17.55 & 18.74 & 21.38 & 21.81 \\
& 23.17 & 24.61 & 27.99 & 55.26 & & & & \\
FN0 & 19.89 & & & & & & & \\
FH0 & 6.88 & 11.82 & 18.56 & 34.44 & & & & \\
FN3 & 11.83 & 18.80 & & & & & & \\
FH3 & 18.68 & & & & & & & \\
\hline
\end{tabular}

matrices and its encapsulation products decreases suggest that the molecular interaction among starch, chitosan, and TPP [13] exists. Meanwhile, the product of $\beta$-carotene encapsulated in native starch-chitosan/TPP matrices also shows broad bands at $2 \theta$ of 11.83 and 18.80 , while the one that was encapsulated in hydrolyzed starch-chitosan/TPP matrices shows a broad band at 18.68. From the X-ray diffraction data, it is observed that there is a significant reduction in the number of peaks of $\beta$-carotene encapsulated in the hydrolyzed starch-chitosan/TPP (FH3) compared to that of the hydrolyzed starch-chitosan/TPP blended matrix without $\beta$-carotene (FH0). In contrast, such significant reductions in the number of peaks of $\beta$-carotene are not observed when it is encapsulated in the native starch-chitosan/TPP (FN0 and FN3). This finding indicates that the encapsulation of $\beta$-carotene is more effective to be done in hydrolyzed starch-chitosan/TPP than in native starch-chitosan/TPP matrices. These XRD pattern results corroborated the existence of interaction of starch, chitosan, and TPP in agreement with what has been concluded in the previous study [19].

\section{SEM Analysis}

The SEM images of the results are presented in Fig. 2. It can be seen that the SEM images/morphology of acidhydrolyzed starch does not significantly change from that of the native starch. It is observed that there was a slight addition of indentation to that of hydrolyzed starch granules compared with that of native starch (Fig. 2(a) and 2(b)). Similar results in the SEM image of starch granules after being hydrolyzed were also found in other studies in acid hydrolyzed starch synthesis [26]. The structure of dried particles is influenced by how the particle dried. Spray drying tends to produce spherical particles with a smooth surface, while the freeze-drying process tends to produce non-spherical particles [27].

The SEM images of blending of starchchitosan/TPP matrices (Fig. 2(d) and 2(e)) and the encapsulation products (Fig. $2(\mathrm{f})$ and $2(\mathrm{~g})$ ) indicate that they are not perfectly spherical but tend to follow the SEM image of chitosan with a non-sharp irregular shape (Fig. 2(c)). These images indicate that starch and chitosan are compatible with each other in blending matrices. Results of SEM analysis support the conclusion of XRD data in this research, as well as the FTIR analysis of our preliminary study [19].

\section{TEM Analysis}

TEM analysis was performed to determine the size of the microparticles in a dry state. TEM images of encapsulation products are presented in Fig. 3.

Fig. 3(a) and 3(b) show agglomerated particles, while Fig. 3(c) and 3(d) show single particles of encapsulation products. The single-particle size of FH3 is smaller than FN3. The morphology of encapsulation products is round with clear boundaries that are different from the SEM analysis. This is due to SEM images taken from a dry state deposited on carbon, while TEM images taken from samples are dispersed in distilled water before drying. When dispersed in distilled 


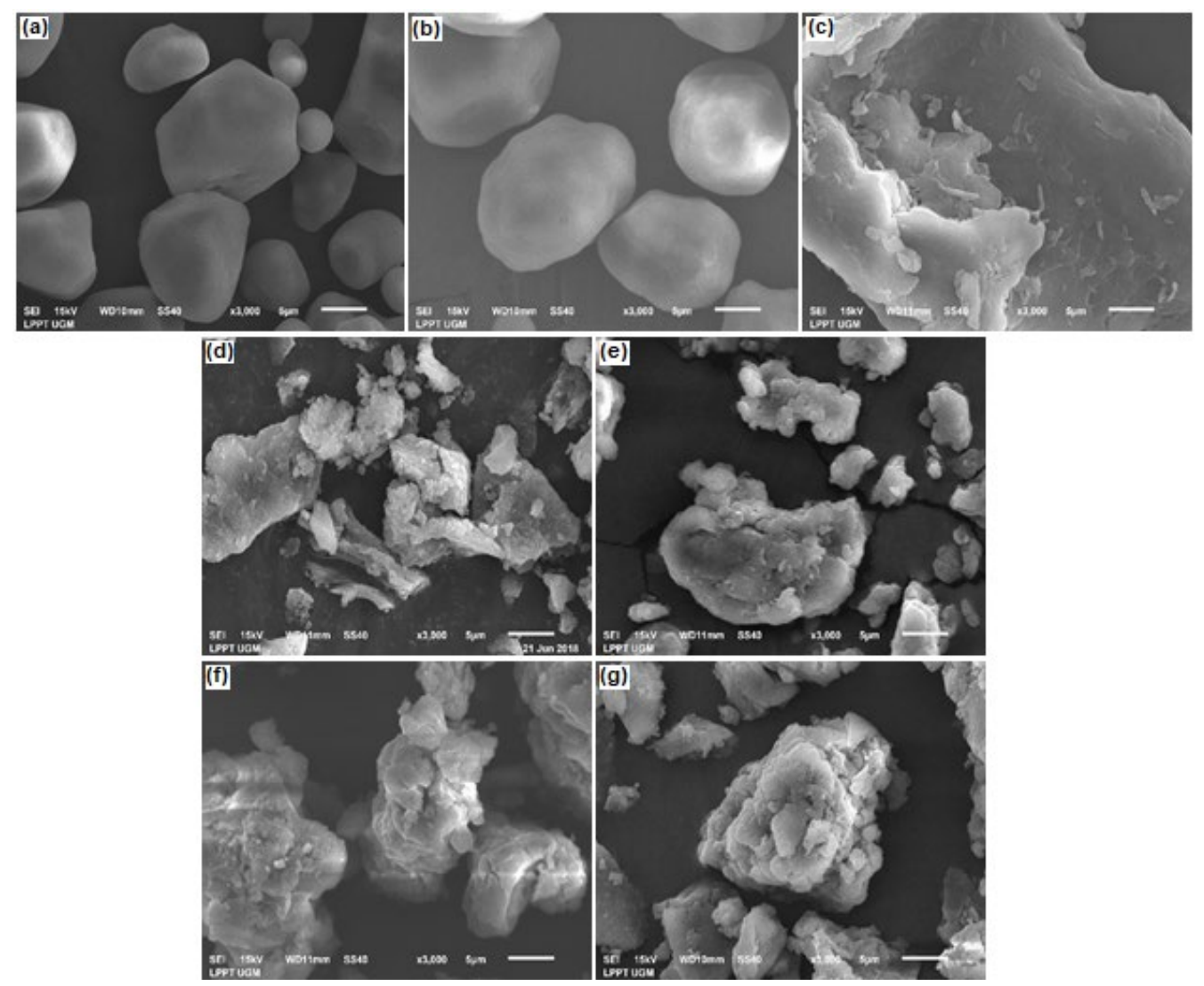

Fig 2. SEM images of matrix materials: (a) starch, (b) hydrolyzed starch, and (c) chitosan; blended matrices without $\beta$-carotene: (d) FN0 and (e) FH0; encapsulation products: (f) FN3 and (g) FH3
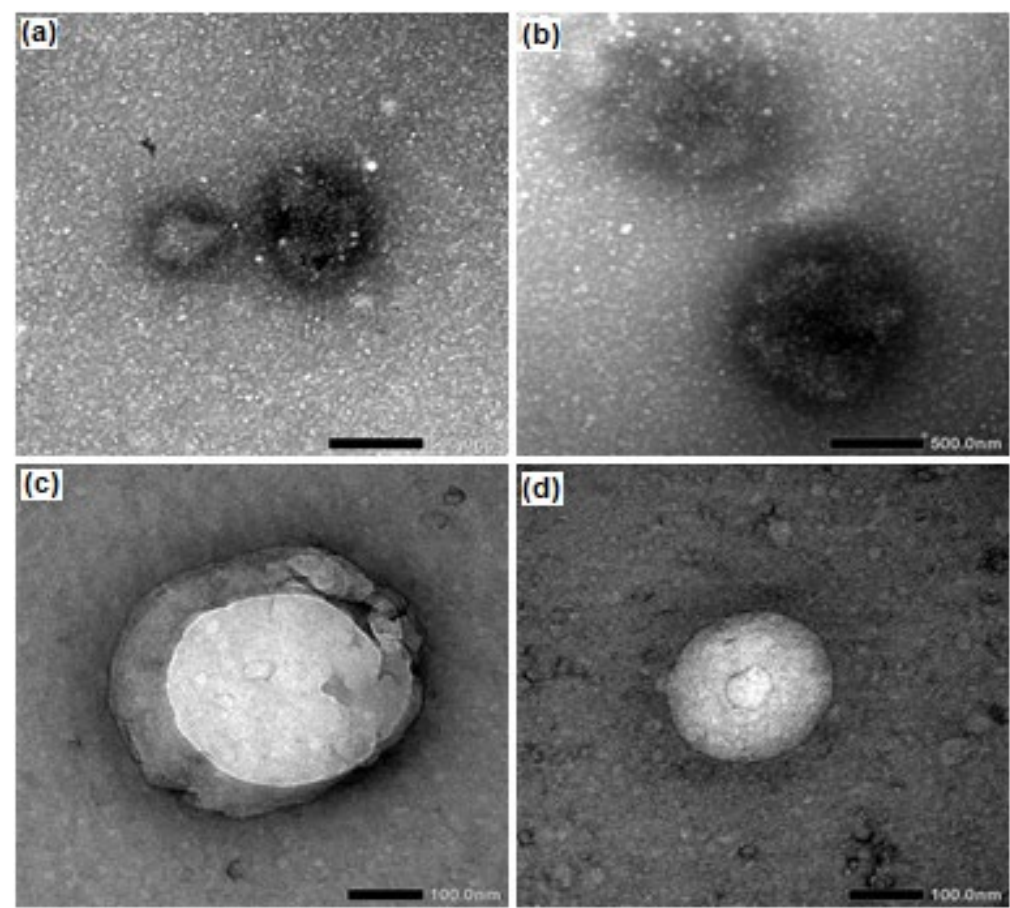

Fig 3. TEM images of encapsulation products: (a) FN3 at 10,000 magnification, (b) FH3 at 10,000 magnification, (c) FN3 at 40,000 magnification, and (d) FH3 at 40,000 magnification 
water, the particles separate well and in a state of relaxation, so when dried, they are more rounded. In addition, the obtained SEM images suggest that the particles are agglomerated. In the FN3 and FH3 samples, the darker colored part is the blended starch-chitosan/TPP matrix because this part is more hydrophilic and dense. This proves that $\beta$-carotene is successfully encapsulated in the matrix.

\section{The Effects of Weight Ratio of Starch to Chitosan on EE and LC}

The effects of starch-to-chitosan weight ratio on EE and LC of $\beta$-carotene encapsulated in the matrix of hydrolyzed starch-chitosan/TPP (FH) and the matrix of native starch-chitosan/TPP (FN) are presented in Fig. 4. In this experiment, we have used various weight ratios of starch to chitosan, e.g., $0.25,0.43,1.00,2.33$, and 4.00 , the constant addition of $\beta$-carotene (10 mg), and fixed TPP addition level of $600 \mathrm{mg}$ (Table 1). EE and LC of FH are consistently higher than those of FN (the mean of EE FN 25.94-34.61\%, EE FH 27.04-34.64\%, LC FN 1.27$1.51 \mathrm{mg} / \mathrm{g}$, and LC FH $1.33-1.70 \mathrm{mg} / \mathrm{g}$ ). This fact was probably due to the increasing of shorter chains of amylose in hydrolyzed starch $[10,25]$ and the increase of the quantity of linear chains similar to amylose [26-27] as mentioned above. The shorter amylose chains and linear chains similar to amylose have more tendency to dissolve in water and make a continuous network by hydrogen

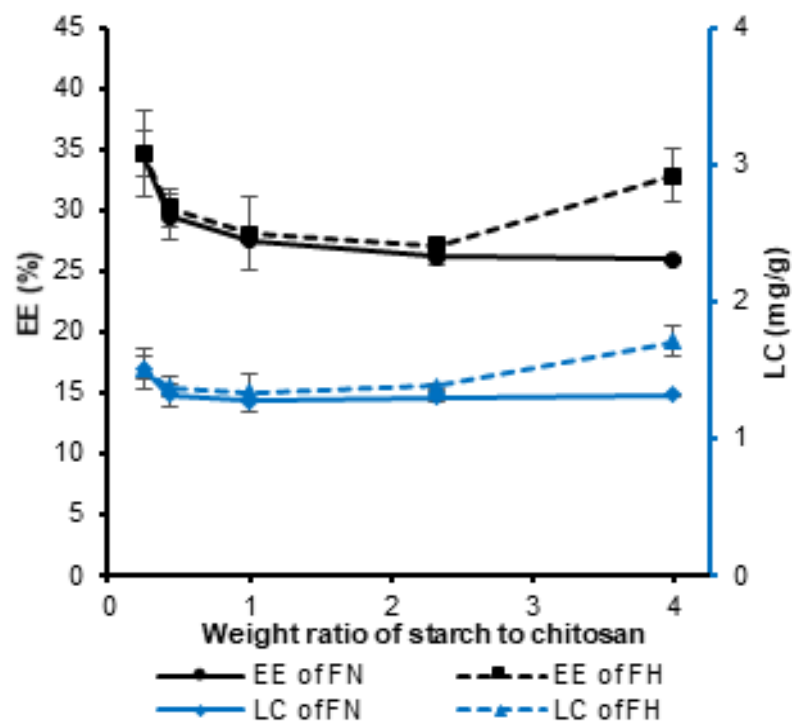

Fig 4. Effects of weight ratio of starch to chitosan on EE and LC bonds with itself or with chitosan/TPP, producing a gel structure that traps $\beta$-carotene in the structure $[10,25]$. Loksuwan [10] has also reported that acid modification of starch by spray drying method as a single matrix in $\beta$-carotene encapsulation increases the efficiency and loading capacity of $\beta$-carotene encapsulation. These results suggest that hydrolyzed starch has a better capability to entrap $\beta$-carotene than the native one.

At the weight ratio of starch to chitosan of 0.251.00, it is observed that EE and LC of FN and FH have a similar trend, namely the increasing proportion of chitosan in the matrices enhances the EE and LC. Nevertheless, in the ranges of starch-to-chitosan weight ratio of 1.00-4.00, the additional portion of starch increases the $\mathrm{EE}$ and $\mathrm{LC}$ of FH, but it is not for FN. These results are in good agreement with what has been reported by Subramanian et al. [12] suggesting that the excess portion of the polymer, both starch, and chitosan, in the weight ratio of starch to chitosan up to 1.00 results in the increase of EE and LC.

\section{Effects of $\beta$-carotene Addition Level on EE and LC}

The effects of the $\beta$-carotene addition level on EE and LC of $\beta$-carotene encapsulated in the matrix of hydrolyzed starch-chitosan/TPP (FH), and native starch-chitosan/TPP (FN) are presented in Fig. 5. In this part of the experiment, a fixed weight ratio of starch to

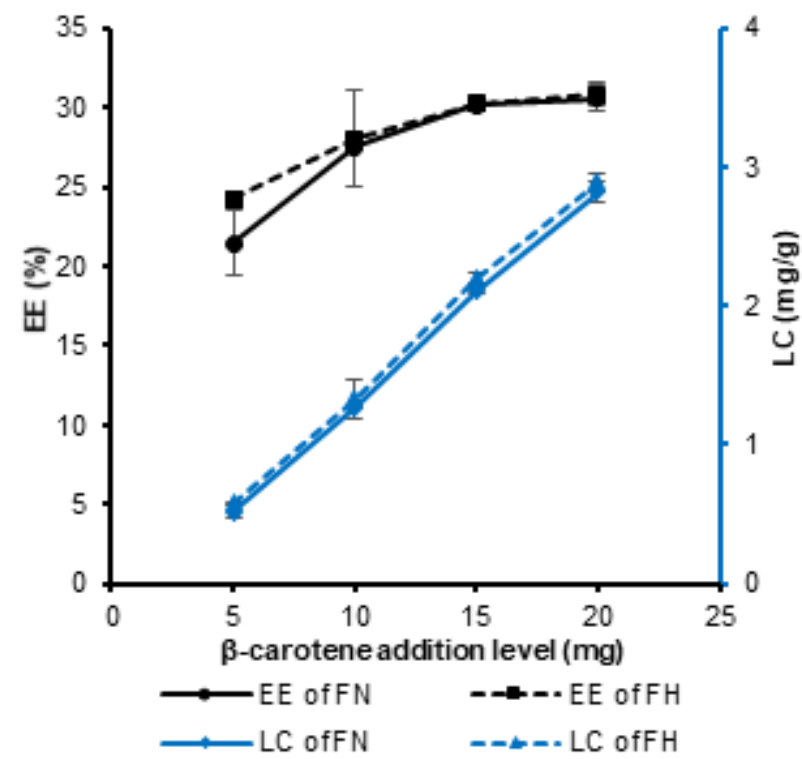

Fig 5. Effects of $\beta$-carotene addition level on EE and LC 
chitosan of 1.00 and a constant TPP addition level of $600 \mathrm{mg}$ were used, while $\beta$-carotene addition level was varied in the range of $5,10,15$, and $20 \mathrm{mg}$ (Table 1). The trends of data obtained here are in line with those observed for the effect of the weight ratio of starch to chitosan previously discussed, e.g., increasing $\beta$-carotene addition gives rise to higher observed $\mathrm{EE}$ and LC in FH as compared to those found in FN (the mean of EE FN 21.47-30.59\%, EE FH 24.2-29.05\%, LC FN 0.52-2.82 mg/g, and LC FH $0.58-2.89 \mathrm{mg} / \mathrm{g}$ ).

The increase in the $\beta$-carotene addition level of 5$10 \mathrm{mg}$, both in $\mathrm{FH}$ and $\mathrm{FN}$, results in significant increases in LC and EE. However, in the $\beta$-carotene addition level of $10-20 \mathrm{mg}$, the significant increase in LC is not accompanied by a significant increase in EE. These results suggest that in the range of 5-20 $\beta$-carotene addition levels, the matrices have not reached their saturated condition, and therefore, they are still capable of trapping $\beta$-carotene. However, the increase of trapped $\beta$-carotene in the matrices resulted from the addition level of $\beta$-carotene in the range of $10-20 \mathrm{mg}$ could not enhance its EE. This is probably due to the fact that the higher the addition level of $\beta$-carotene in the ethanol, the lower the difference in surface tension between the solvent (ethanol) phase and non-solvent (aqueous) phase [28]. The decrease in surface tension difference between the two phases leads to a weaker Marangoni stress, resulting in the larger droplet of solvent phase [29]. The larger droplets of the solvent phase are more difficult to be entrapped by the matrix system, and it tends to deposit in the outer site of the resulted micro-particle. This gives rise to an undesired condition where some $\beta$-carotene can be easily re-released during the washing step using ethanol. In the previous literature [21], it has been reported that in the range of 5-20 mg $\beta$-carotene addition level, LC tends to increase, but EE was found to decrease when a similar method was used by using only starch for the matrix. Interestingly, in our results, we observe that the increasing LC in a similar addition level is still accompanied by the increase of EE. This finding clearly reveals the role of the addition of chitosan/TPP in increasing starch capability as a matrix of $\beta$-carotene encapsulation.

\section{The Effects of TPP Addition Level on EE and LC}

The effects of the TPP addition level in the ranges of 400-800 mg on EE and LC of $\beta$-carotene encapsulated in the matrix of hydrolyzed starch-chitosan/TPP (FH) and native starch-chitosan/TPP (FN) are presented in Fig. 6. In this section, the fixed weight ratio of starch to chitosan of 1.00 and constant $\beta$-carotene addition level of $10 \mathrm{mg}$ were used, while the TPP addition level was varied in the range of $400,500,600,700$, and $800 \mathrm{mg}$ (Table 1). A relatively narrow range of TPP addition levels between 400 and $800 \mathrm{mg} / \mathrm{L}$ has been chosen in this study because the additions of TPP with the weight ratio of starch and chitosan lower than $400 \mathrm{mg}$ while keeping the weight ratio of starch to chitosan of 1.00 is not effective as shown by the extremely low yields of the encapsulation products. On the other hand, the addition of TPP larger than $800 \mathrm{mg}$ at the weight ratio of starch to chitosan of 1.00 results in fast agglomeration and precipitation of the matrix mixture even before the $\beta$-carotene addition step could be done.

Fig. 6 shows that the EE and LC of FH were slightly higher than FN. Again, this fact supports the previous conclusion that hydrolyzed starch-chitosan/TPP is the better matrix for $\beta$-carotene encapsulation (the mean of EE FN 24.44-28.31\%, EE FH 27.62-29.05\%, LC FN $1.11-1.35 \mathrm{mg} / \mathrm{g}$, and LC FH $1.30-1.37 \mathrm{mg} / \mathrm{g}$ ). In the range

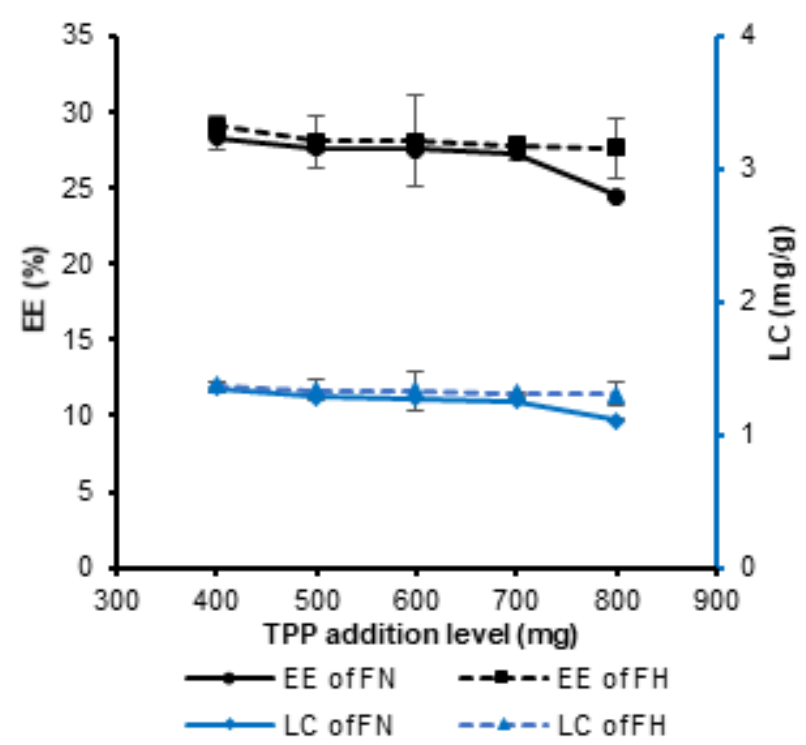

Fig 6. Effects of TPP addition level on EE and LC 
of 400-800 mg of the TPP addition level, the increase in the TPP addition level has no significant effect on EE and LC of FH. On the other hand, similar results are found in $\mathrm{FN}$ in the range of $400-700 \mathrm{mg}$. However, in the range of 700-800 mg TPP addition level, a decrease both in EE and $\mathrm{LC}$ is observed. The decrease in $\mathrm{EE}$ and $\mathrm{LC}$ is probably due to the existence of an excess of TPP, which saturates the native starch, causing the matrix to become tighter, and as a result, $\beta$-carotene tends to be trapped in the outer surface of the matrix. The trapped $\beta$-Carotene in the surface is easily dissolved during the experimental step of ethanol washing after the centrifugation stage. This situation explains the small results of $\beta$-carotene found in the encapsulation products. Similar results have also been found in another study [13] suggesting that increasing concentration of TPP in the matrices tends to reduce EE and LC of encapsulation products.

\section{Storage Stability Evaluation}

Fig. 7 displays the storage stability of $\beta$-carotene encapsulated in the various matrices of native starch only (NS), hydrolyzed starch only (HS), native starchchitosan/TPP (FN3), and hydrolyzed starchchitosan/TPP (FH3). It is clearly observed that the storage stability of $\beta$-carotene increases when a combination of starch-chitosan/TPP matrix is used compared to those of using starch only, native starch, and hydrolyzed starch. The replacement of native starch with hydrolyzed starch in the matrix of starch-chitosan/TPP slightly increases the stability of $\beta$-carotene against UV light (Fig. 7(a)) and heat (Fig. 7(b) and 7(c)). The reaction rate constants and the half-life of the sample degradation have been determined according to the first-order reaction equation, as presented in Table 3. The reaction kinetics of $\beta$-carotene degradation has been found to follow the first-order reaction rate as obviously can be seen from its coefficient of determination $\left(\mathrm{R}^{2}\right)$ value, which is in the range of 0.9561 to 0.9976 . The longest half-life in every storage condition is shown by the matrix of FH3. The shortest half-life was shown by NS. The enhancement of the stability of $\beta$-carotene by modification of starch trough hydrolysis reaction has also been reported by Spada et al. [11]. In his paper, he reported that by using hydrolyzed pinhão (Araucaria angustifolia seeds) starch as a matrix, the rate constant $(\mathrm{k})$ calculated using firstorder kinetic model lower $\left(\mathrm{k}=0.014-0.017\right.$ days $^{-1}$ in the dark at $\left.10-25^{\circ} \mathrm{C}\right)$ than its native starch $(\mathrm{k}=0.048-$ 0.076 days $^{-1}$ in the dark at $10-25{ }^{\circ} \mathrm{C}$ ). The lower the $\mathrm{k}$, the higher the storage stability of $\beta$-carotene. In this research, the storage stability of $\beta$-carotene encapsulated in the starch matrices, both native and hydrolyzed starch, increases significantly by the addition of chitosan into the matrix system. The rate constant $(\mathrm{k})$ calculated using first-order kinetic model lower $(\mathrm{k}=0.0072$ 0.0711 days $^{-1}$ in the dark at $5-30{ }^{\circ} \mathrm{C}$ ) than its native starch $\left(\mathrm{k}=0.0107-0.0761\right.$ days $^{-1}$ in the dark at $\left.5-30^{\circ} \mathrm{C}\right)$, while in the presence of UV light, the $\mathrm{k}$ much higher than in the dark. The half-life of encapsulation product in the order of $\mathrm{FH} 3>\mathrm{FN} 3>\mathrm{HS}>\mathrm{NS}$ as reflected from its $k$. The cause of this result may have been due to the capacity of chitosan in film-forming and antioxidant
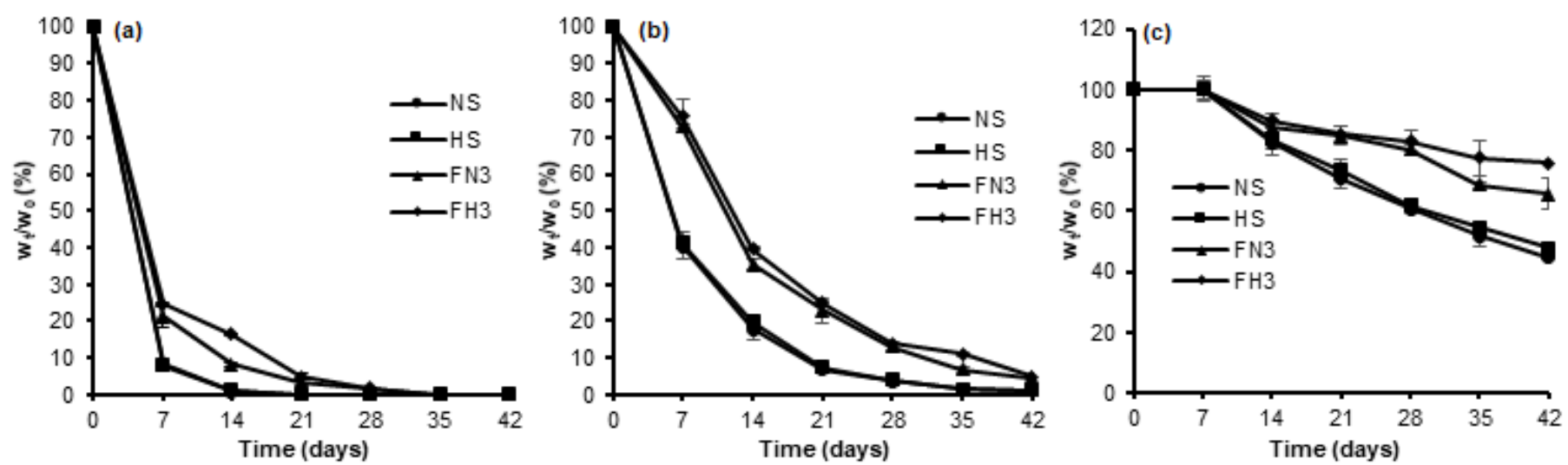

Fig 7. Storage stability of encapsulation products (a) in the presence of UV light at ambient temperature, (b) in the dark at ambient temperature, and (c) in the dark at $(5 \pm 1)^{\circ} \mathrm{C}$ 
Table 3. Coefficient of determination $\left(R^{2}\right)$ and kinetic parameters in the storage stability test of $\beta$-carotene encapsulation products

\begin{tabular}{|c|c|c|c|c|}
\hline Sample code & $\mathrm{R}^{2}$ & Regression Equation & $\mathrm{k}\left(\mathrm{day}^{-1}\right)$ & $\mathrm{t}_{0.5}$ (day) \\
\hline \multicolumn{5}{|c|}{ Stored in the presence of UV radiation, ambient temperature } \\
\hline NS & 0.9976 & $y=-0.3341 x-0.0665$ & 0.3341 & 2.07 \\
\hline HS & 0.9961 & $y=-0.3221 x-0.0816$ & 0.3221 & 2.15 \\
\hline FN3 & 0.9831 & $y=-0.1478 x-0.2683$ & 0.1478 & 4.69 \\
\hline FH3 & 0.9820 & $y=-0.1367 x-0.1251$ & 0.1367 & 5.07 \\
\hline \multicolumn{5}{|c|}{ Stored in the dark, ambient temperature } \\
\hline NS & 0.9835 & $y=-0.1088 x-0.1695$ & 0.109 & 6.36 \\
\hline HS & 0.9836 & $y=-0.1078 x-0.1377$ & 0.1078 & 6.43 \\
\hline FN3 & 0.9948 & $y=-0.0761 x+0.0842$ & 0.0761 & 9.11 \\
\hline FH3 & 0.9879 & $y=-0.0711 x+0.0951$ & 0.0711 & 9.75 \\
\hline \multicolumn{5}{|c|}{ Stored in the dark, $(5 \pm 1)^{\circ} \mathrm{C}$} \\
\hline NS & 0.9808 & $y=-0.0206 x+0.0756$ & 0.0205 & 33.80 \\
\hline HS & 0.9799 & $y=-0.019 x+0.0688$ & 0.0189 & 36.67 \\
\hline FN3 & 0.9561 & $y=-0.0108 x+0.0379$ & 0.0107 & 64.77 \\
\hline $\mathrm{FH} 3$ & 0.9640 & $y=-0.0073 x+0.012$ & 0.0072 & 96.25 \\
\hline
\end{tabular}

function, thus, it is able to preserve $\beta$-carotene from degradation by light and heat [14].

\section{- CONCLUSION}

It has been shown that the capability of starch as a matrix of $\beta$-carotene encapsulation can be enhanced by using hydrolyzed starch and a combination of starch with cross-linked chitosan using TPP as a cross-linker as matrices. The crystallinity of the encapsulation products decreases due to the occurrence of the interaction between starch, chitosan, and TPP. XRD and SEM result has confirmed the good compatibility of the mixture among starch, chitosan, and TPP. The storage stability of $\beta$-carotene is enhanced by the encapsulation of $\beta$ carotene in the starch-chitosan/TPP matrix. The highest results of EE and LC, as well as the longest storage stability of $\beta$-carotene encapsulated in the matrices of hydrolyzed starch-chitosan/TPP, support the potential and promising use of this matrix combination in the encapsulation of other hydrophobic drugs.

\section{- ACKNOWLEDGMENTS}

The authors would like to thank the Directorate General of Higher Education, Ministry of Research, Technology, and Higher Education, The Republic of
Indonesia (Kemenristekdikti), for the research funding through the Doctoral Dissertation Research Grant (PDD) with contract number 2885/UN1.DITLIT/DITLIT/LT/2019.

\section{- REFERENCES}

[1] Chávarri, M., Marañón, I., and Villarán, M.C., 2012, "Encapsulation technology to protect probiotic bacteria" in Probiotics, Eds. Rigobelo, E.C., IntechOpen, Rijeka, 501-540.

[2] Nedovic, V., Kalusevic, A., Manojlovic, V., Levic, S., and Bugarski, B., 2011, An overview of encapsulation technologies for food applications, Procedia Food Sci., 1, 1806-1815.

[3] Joye, I.J., and McClements, D.J., 2014, Biopolymerbased nanoparticles and microparticles: Fabrication, characterization, and application, Curr. Opin. Colloid Interface Sci., 19 (5), 417-427.

[4] Gul, K., Tak, A., Singh, A.K., Singh, P., Yousuf, B., and Wani, A.A., 2015, Chemistry, encapsulation, and health benefits of $\beta$-carotene - A review, Cogent Food Agric., 1 (1), 1018696.

[5] Yuan, Y., Gao, Y., Zhao, J., and Mao, L., 2008, Characterization and stability evaluation of $\beta$ carotene nanoemulsions prepared by high pressure 
homogenization under various emulsifying conditions, Food Res. Int., 41 (1), 61-68.

[6] Gu, L., Su, Y., Zhang, M., Chang, C., Li, J., McClements, D.J., and Yang, Y., 2017, Protection of $\beta$-carotene from chemical degradation in emulsionbased delivery systems using antioxidant interfacial complexes: Catechin-egg white protein conjugates, Food Res. Int., 96, 84-93.

[7] Yang, J., Han, S., Zheng, H., Dong, H., and Liu, J., 2015, Preparation and application of micro/ nanoparticles based on natural polysaccharides, Carbohydr. Polym., 123, 53-66.

[8] Fathi, M., Martín, Á., and McClements, D.J., 2014, Nanoencapsulation of food ingredients using carbohydrate based delivery systems, Trends Food Sci. Technol., 39 (1), 18-39.

[9] Fouladi, E., and Nafchi, A.M., 2014, Effects of acidhydrolysis and hydroxypropylation on functional properties of sago starch, Int. J. Biol. Macromol., 68, 251-257.

[10] Loksuwan, J., 2007, Characteristics of microencapsulated $\beta$-carotene formed by spray drying with modified tapioca starch, native tapioca starch and maltodextrin, Food Hydrocolloids, 21 (56), 928-935.

[11] Spada, J.C., Noreña, C.P.Z., Marczak, L.D.F., and Tessaro, I.C., 2012, Study on the stability of $\beta$ carotene microencapsulated with pinhão (Araucaria angustifolia seeds) starch, Carbohydr. Polym., 89 (4), 1166-1173.

[12] Subramanian, S.B., Francis, A.P., and Devasena, T., 2014, Chitosan-starch nanocomposite particles as a drug carrier for the delivery of bis-desmethoxy curcumin analog, Carbohydr. Polym., 114, 170-178.

[13] Perez, J.J., and Francois, N.J., 2016, Chitosan-starch beads prepared by ionotropic gelation as potential matrices for controlled release of fertilizers, Carbohydr. Polym., 148, 134-142.

[14] Peng, H., Xiong, H., Li, J., Xie, M., Liu, Y., Bai, C., and Chen, L., 2010, Vanillin cross-linked chitosan microspheres for controlled release of resveratrol, Food Chem., 121 (1), 23-28.
[15] de Vos, P., Faas, M.M., Spasojevic, M., and Sikkema, J., 2010, Encapsulation for preservation of functionality and targeted delivery of bioactive food components, Int. Dairy J., 20 (4), 292-302.

[16] Raguzzoni, J.C., Delgadillo, I., and Lopes da Silva, J.A., 2016, Influence of a cationic polysaccharide on starch functionality, Carbohydr. Polym., 150, 369377.

[17] Bajer, D., and Kaczmarek, H., 2010, Study of the influence OV UV radiation on biodegradable blends based on chitosan and starch, Prog. Chem. Appl. Chitin Deriv., 15, 17-24.

[18] Lawal, O.S., and Adebowale, K.O., 2005, Physicochemical characteristics and thermal properties of chemically modified jack bean (Canavalia ensiformis) starch, Carbohydr. Polym., 60 (3), 331-341.

[19] Lestari, A.D.N., Mudasir, Siswanta, D., and Martien, R., 2018, Preliminary study on microprecipitation of $\beta$-carotene in starch/chitosan/TPP (tripolyphosphate) matrices: Effects of weight ratio of starch/chitosan, AIP Conf. Proc., 2049, 020045.

[20] Rampino, A., Borgogna, M., Bellich, B., Blasi, P., Virgilio, F., and Cesàro, A., 2016, Chitosan-pectin hybrid nanoparticles prepared by coating and blending techniques, Eur. J. Pharm. Sci., 84, 37-45.

[21] Kim, J.Y., and Huber, K.C., 2016, Preparation and characterization of corn starch- $\beta$-carotene composites, Carbohydr. Polym., 136, 394-401.

[22] Rutz, J.K., Borges, C.D., Zambiazi, R.C., da Rosa, C.G., and da Silva, M.M., 2016, Elaboration of microparticles of carotenoids from natural and synthetic sources for applications in food, Food Chem., 202, 324-333.

[23] Chu, B.S., Ichikawa, S., Kanafusa, S., and Nakajima, M., 2007, Preparation and characterization of $\beta$ carotene nanodispersions prepared by solvent displacement technique, J. Agric. Food Chem., 55 (16), 6754-6760.

[24] Ferranti, V., Marchais, H., Chabenat, C., Orecchioni, A.M., and Lafont, O., 1999, Primidoneloaded poly-e-caprolactone nanocapsules: 
Incorporation efficiency and in vitro release profiles, Int. J. Pharm., 193 (1), 107-111.

[25] Chen, L., McClements, D.J., Zhang, H., Zhang, Z., Jin, Z., and Tian, Y., 2019, Impact of amylose content on structural changes and oil absorption of fried maize starches, Food Chem., 287, 28-37.

[26] Ulbrich, M., Beresnewa-Seekamp, T., Walther, W., and Flöter, E., 2016, Acid-thinned corn starchimpact of modification parameters on molecular characteristics and functional properties, Starch/Stärke, 68, 399-409.
[27] Hasani, S., Ojagh, S.M., and Ghorbani, M., 2018, Nanoencapsulation of lemon essential oil in Chitosan-Hicap system. Part 1: Study on its physical and structural characteristics, Int. J. Biol. Macromol., 115, 143-151.

[28] Hsin, W.L., Sheng, Y.J., Lin, S.Y., and Tsao, H.K., 2004, Surface tension increment due to solute addition, Phys. Rev. E, 69 (31), 1-8.

[29] Blanchette, F., Messio, L., and Bush, J.W.M., 2009, The influence of surface tension gradients on drop coalescence, Phys. Fluids, 21 (7), 072107. 